\title{
The Research on Enterprise Manufacture Integrated and Collaborative Commerce System
}

\author{
Hechao Wang ${ }^{1}$,Huijuan Shang', Wensheng Liu $^{2}$ \\ 1 School of Management, China University of Mining and Technology, \\ Xuzhou, 221008, China \\ 2 Information center of Xu Zhou Cigarettes Factory, Xuzhou, 221000,China \\ wanghechao@sina.com, liuws@xzjyc.com.cn
}

\begin{abstract}
Global optimization and fast response ability in market cannot be simply achieved by computer automation without considering systematic application integration. The manufacturing enterprises need integrated platform and the coordinated commercial support platform to improve its whole productivity, flexibility, competitiveness and the ability in emergency management. This paper presents an e-commerce project at Xuzhou Cigarettes Factory with Jiangsu cigarette industrial group. We introduced the current information-based situation of the Xuzhou Cigarettes Factory with Jiangsu cigarette industrial group, identified the key problems and bottlenecks in the enterprise's management, and proposed the solution for enterprises' manufacturing integration and collaborative commerce. Our solution could be referred and used for information construction in manufacturing enterprises.
\end{abstract}

\section{In troduction}

As the informationize manufacture industry develops deeply, it is the enterprises' research and practice hot-spot that improving enterprises' productivity rate, flexibility, changeable management ability, and quick response ability to the market need by the construction of manufacture integrated and collaborative commerce platform. Based on the case of application of Ecommerce project of the cigarette industrial group of Jiangsu Xuzhou Cigarettes Factory, this thesis researches on the enterprise manufacture integrated and collaborative commerce system.

Please use the following format when citing this chapter:

Wang, II., Shang, II., I,iu, W., 2007, in IFIP Intcrnational Federation for Information Processing, Volume 251, Integration and Innovation Orient to E-Society Volume1, Wang, W. (Fds), (Boston: Springer), pp. 155-166. 


\section{The Current Information Situation About Xuzhou Cigarettes Factory.}

The Xu Zhou Cigarettes Factory built on 1939, which is one of the large-scale Chinese tobacco industry key enterprises. Now it has staff and worker more than 2,000 people, has 550,000 boxes cigarettes production scale and 800,000 boxes cigarettes production ability. It's fixed assets original value amounting to $1,700,000,000$ Yuan. It possesses a leaf silk high expansion system silk production line which is first one in our whole country and has international leading level. It also has a scientific and perfect quality control system. It considered being a profession "digitalization tobacco enterprise" experimental build unit and demonstration unit. Xu Zhou Cigarettes Factory has been determined as one after another" the nation-wide tobacco profession key enterprise of $10 \%$ of technical reformation", " 36 profession key enterprises " and "profession informative advanced enterprise ", becomes the main force of Chinese tobacco industry.

As an advanced Information construction enterprise in tobacco industry, Xu Zhou Cigarettes Factory has already successively been put into effect ERP system, Office Automation System, country bureau production Information projects such as managerial decision making management system, CRM system, financial affairs system It has been put into effect systems in the field of enterprise manufacture automation making silk production line collection charging system, the flake production line for assembling charging system, electric power air-conditioning control system etc; It has established the overhead warehouse of raw material automation formula , and has assisted in the field of logistics automation to expect that the overhead warehouse and the robot automation distribution system , attachment the overhead warehouse and so on; each system runs fine and has brought the important effect for managing the enterprise manufacture.

Though Information construction in the industry starting is earlier, some $\mathrm{Xu}$ Zhou Cigarettes Factory construction information system was build in order to be fit unlike business purpose, these systems' usage platform, program develop language and information transfer standard diversity, causing enterprise inside resource not able to cooperate effectively, some phenomenon, as certain dissipation and running efficiency has not highly brought out, the realization not product a link in enterprise manufacture integration, the business administration does not have an effective information analysis system tier. It doesn't has a effective closed cycle taking form between down-stream enterprise, and has no way to change the data into useful information. The inherent potential of enterprise is not brought into full play, and in certain degree.

\section{The Urgent Need Of Putting Enterprise Fabrication Integration And Collaborative Commerce System Into Practice For Xuzhou Cigarettes Factory}

Owing the understanding of urgent need industry competes and oneself develop, know urgency and necessity that the project builds! 
(1) Industry competition urgent demand enterprise acceleration construction fabrication integration and Collaborative Commerce system.

Being accompanying prompt tobacco enterprise dilation's is that product quantity straight line rises, the market is control by seller rather then buyer. Some companies have to close for an bad management. At present, the whole national tobacco industry already develops from the amounts dilation to the brand, to quality.

More direct competition depends on of the opening to the outside world that is tobacco produces also already opens to the foreign merchant: Already allow foreign capital tobacco to enter China with joint investment form. At present only the channel not open to the outside, and it difficultly to hold such condition. The cigarette has as fleetness consumer goods, but replacement, this consume manufacture, supply of material, marketing have proposed that very highly demand of characteristic to cigarette to be to need "to depend on amounts, coming to develop markets depending on being satisfied with in time". Except the abundance guarantee supply of material, returning back to the channel smoothness such that swear to be authorized for dispatch of, be delivered goods, retail broad spreading point, in short, to be needing to ensure that the consumer all can buy in any moment, any place. Marketplace competing in altitude is out of stock otherwise, in a single day under the situation, may there is somebody being equivalent to your place right away immediately. But need to reach this one target, Xu Zhou Cigarettes Factory "can't be separated from IT absolutely", need to create integrated coordination business system owing to enterprise more.

(2) Puts enterprise fabrication integration and coordination business system into practice is an Information tobacco industry desire for development.

Tobacco Monopoly Administration has suggested three big Information construction targets in 2003, that is system integration, resource integrate, information shares. Then it made three uniting clear further afterwards, has been big industry information system uniting a network, uniting platform, uniting a data base, and concentrating on planning and putting three into practice, Namely: The cigarette produces managerial decision-making management system, Office Automation System, Electronic Commerce system. Xu Zhou Cigarettes Factory should puts enterprise fabrication integration and coordination business system into practice as soon as possible, and preparation the industry produce managerial decision making management system and electron business system carrying out integration.

Support "integrated inside and coordination outside" enterprise creates integration and meets the need of business system accords with the Information desire for development of industry, the energy and industry system realize "system integration, resource integrates, information enjoys ".

Request putting enterprise fabrication integration and coordination business affairs into practice being Xu cigarette informationize planning.

(1) Facing population development strategy administration needs.

Core business of enterprise develops: marketing, $R \& D$, manufacture, logistics need supported with Collaborative Commerce affairs platform. 


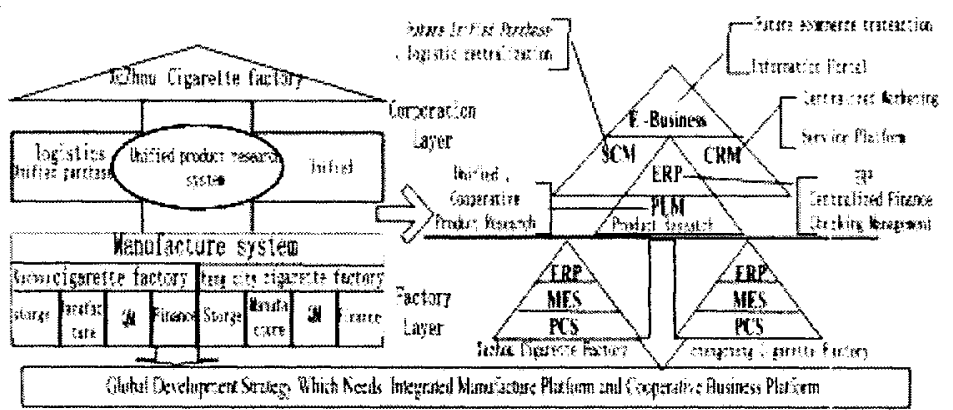

Figure.1 Support Platform

(2) Facing the needs of information strategy plan-------digitization tobacco.

"Digitization tobacco" idea, whose purpose are links, each technological process with informationize transfixion tobacco industry production management control each, information changes complex and volatile tobacco being not bad the quantization data, passes numerical analysis, development of estate provides the basis making policy to every enterprise even entire. Austerity developing and facing according to enterprise is real; Xu Zhou Cigarettes Factory must realize enterprise digitization, concrete doctrine: Procedure of production digitization, fabrication is equipped with digitization, design digitization, manage digitization.

(3) The manufacture that faces enterprise is integrated into demand.

Xu Zhou Cigarettes Factory's condition at present is:

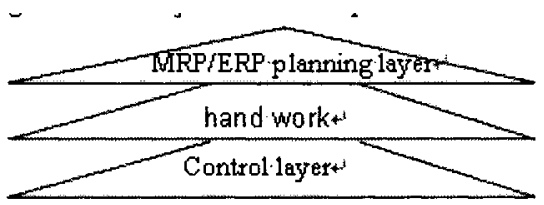

Figure. 2 Relationship Layer

Enterprise production program system high when go up, cause scene to become dark box; function of auto machine does not get integration, forming automatic isolate lan inland produce bottleneck.

Producing organization construction and business process repeat, is unhappiness, conducted efficiency is low, need to carry out the business process of the science and organization construction that optimizes to form efficiency;

Now lack effective information communication and integration between each system implemented, it is serious that piece cuts apart, can not manage for that data resource carries out effective integration;

Information collect is not put into effect in the line and detecting equipment mass, the mass process control does not perfect, quality analysis does not prevent an off-test product from flowing into a marketplace on timely, unable secondary headstream; 
Online and detection equipment quality information collection has not been implemented, the process control of quality is un-sound, quality analysis is not prompt, can not prevent from fountainhead that rejected product flows in market;

The process that has not realized major production process is trailed, can not trace back the source that product quality problem produces, can not accomplish the meticulous management in process;

Need to establish enterprise therefore to make integrated system, connect the planned same workshop schoolwork control of upper levels of management system on-the-spot, solve the control layer on-the-spot and the management level of upper levels join, the information that realize production to control layer, the automatic layer of commodity circulation and ERP system share, the science and promptness that realizes the degree layer of middle tone melt, meticulous melt. Accept production actual data feedbacks to ERP system, again instructing the production of the management system of upper levels to give the process of arriving control layer(PCS); About company know the control equipment on-the-spot and the platform of business management, realization data have no seam connection with share.

(4) The business that faces market cooperates with demand.

Through manufacture integrated construction, Xu Zhou Cigarettes Factory must control its' inside industrial operation management form bottom - - production manages execution - the systems such as ERP and CRM - - decision-making system to support system to realization the data flow of two-way. It is a good internal data foundation for Collaborative Commerce construction establishes. But found enterprise cooperate with commercial system still need establish E-business systematic commodity circulation management system etc. between the upper-lower enterprise that closely related with enterprise. With raising knowledge shares degree and enterprise innovation ability between close enterprise behaviors, it is so unceasing to raise enterprise competitive ability.

Through the construction of collaborative commerce, $\mathrm{Xu}$ Zhou Cigarettes Factory will reduce enterprise cost by further using IT, which can promotes the level of business management and raises the core competitiveness of enterprise .

In a word, manufacture integration and melt in collaborative commerce platform for Xu Zhou Cigarettes Factory is imperatively, is extremely urgent!

As the advanced enterprise of tobacco profession informative construction, $\mathrm{Xu}$ Zhou Cigarettes Factory grasps the opportunity that promotes enterprise to develop with IT , implements the project " enterprise manufacture integration and collaborative commerce system", quests of the development way in such hard competitive environmental develops the collaborative commerce practice experience with valuable accumulation. 


\section{The Construction Of Xuzhou Cigarettes Factory Manufacture Integrated And Collaborative Commerce}

\subsection{Construction target}

Taking tobacco profession informative application as background, it takes Xu Zhou Cigarettes Factory overall development strategy as guidance, managing system through optimizing process and organization transform and establishing the tobacco supply chain of " integrate product, supply and marketing ";

By establishment support enterprise the integrated E-business platform of "internal integration, external cooperate with ", and supplementing leading decisionmaking support so raises enterprise operation efficiency, it can promote the level of business management strengthens enterprise core competitiveness.

\subsection{Project content}

Demand has made clearly, how to satisfy the above demand? Especially according to integration, how to be founded? What system this platform should include as well as what function may realize manufacture basically to integrate with cooperates with business?

According to the analyze about $\mathrm{Xu}$ Zhou Cigarettes Factory enterprise manufacture integration with collaborative commerce system comprehensive build table, the major content that determines this project construction is with establishment " internal integration, external cooperate with " integration melts, Ebusiness platform is key, include some following aspects specifically:

Firstly, manufacture integration platform: Build demand around enterprise key business application system, integrate when carrying out the systematic product life management system, manufacture execute system ,supply chain management system on ERP systematic foundation to realize the application of enterprise key business; Revolve around enterprise decision-making support system is shared and integrated for efficiency into the data demand of optimization, establishment enterprise data center, realization enterprise data integration, establish enterprise decision support system on this foundation.

Secondly, integrate in collaborative commerce platform: On the platform of completing enterprise internal manufacture integration, informative application expands outward to enterprise supplier and customer layer, realizes the electron between " supplier - Xu Zhou Cigarettes Factory - tobacco company " to melt trade, promote enterprise external business to cooperate with.

Thirdly, network sustain and apply safety: Integrate and cooperate with the efficient safe operation of commercial system for that effective support enterprise makes, need to reform for that original network carries out upgrade, and establish reliable network, application and the further raisings such as information safe system enterprise garden district net and the communication quality with profession net and internet, ensure that systematic success runs. 


\section{3 Construction scheme}

Xuzhou Cigarette Factory manufacture integration with collaborative commerce system is under the guidance of the enterprise informative frame of overall planning ( as Fig. 3 shows), and on based the analyze foundation for enterprise present informative present situation put forward. From this program frame, we may find out that the informative support system of Xuzhou cigarette factory overall program may divide into 4 levels. It ensures Xuzhou Cigarettes Factory realizes business process innovation with two parts, and melts in coordination the technical guarantee of Ebusiness.

4 levels: Since outside, it is divide into internal network layer, data layer, application systematic layer and decision-making layer from the most basic internal network layer to the application level of E-business, above of those 4 levels, it is the specific application of E-business;

Two parts: Overall manufacture integration consists of enterprise internal and external resource and the integration of internal resource are integrated. Internal resource integration part is the information on the integrated foundation of enterprise key business application system to share, integration, the integration part of internal and external department resource is in internal resource integration, on the application system as well as portals, electronic business platform foundation that joins enterprise two ends specify melt in coordination E-business application.

Network layer: network layer is the basic platform that enterprise internal information resource to share, and the essential condition of IT application system. It is a key point for realizing enterprise melts in coordination the of E-business. Xuzhou Cigarette Factory has established relatively perfect network environment, and established good foundation to implement this project.

Data layer: Data layer covers the demand for service of cigarette industrial enterprise for entire application systematic and enterprise decision-making service. In this project, will found cigarette enterprise data platform, establish enterprise data center, and establish foundation for future enterprise development.

Apply layer: Application systematic construction will combine goal process, carries out unified construction on unified program foundation. This project take the enterprise resource planned management system that had been completed (ERP) and customer relation manage (CRM) as foundation, the further construct management system of supply chain management (SCM) and manufacture execute system (MES) and product life management system (PLM) and decision-making support system and the E-business platform that melts in coordination wait for that core has systematic application.

Decision-making layer: Xuzhou cigarette factory decision supporting support platform (DSS) takes the data center of establishment as core, data warehouse (Data Warehouse) technology as basic, with OLAP and Data Mining tool carries out the supplementary leading decision-making support of enforcement for means system. 
162 The Research on Enterprise Manufacture Integrated and Collaborative Commerce

System

\section{Application System Construction}

\subsection{Manufacture execute system}

(1) Software structural design.

It is the various advantages that combine domestic and international production to manage software to develop the overall objective of this system, foster strengths and circumvent weaknesses, make system reach really practical degree under existing network soft hardware condition. Production manages software the Dot Net and $\mathrm{COM} / \mathrm{DCOM} / \mathrm{COM}+$ that has Microsoft frequently with application configuration, CORBA of object management organization (OMG) and solar tiny system company (SUN Microsystems Inc) J2EE. Since the structural model of Microsoft is more mature, this systematic overall structure may be considered with the structural model of Windows DNA or Dot Net adopts the software structure of $\mathrm{B} / \mathrm{S}$ or fake $\mathrm{B} / \mathrm{S}$ for foundation. Following Fig.4 shows:

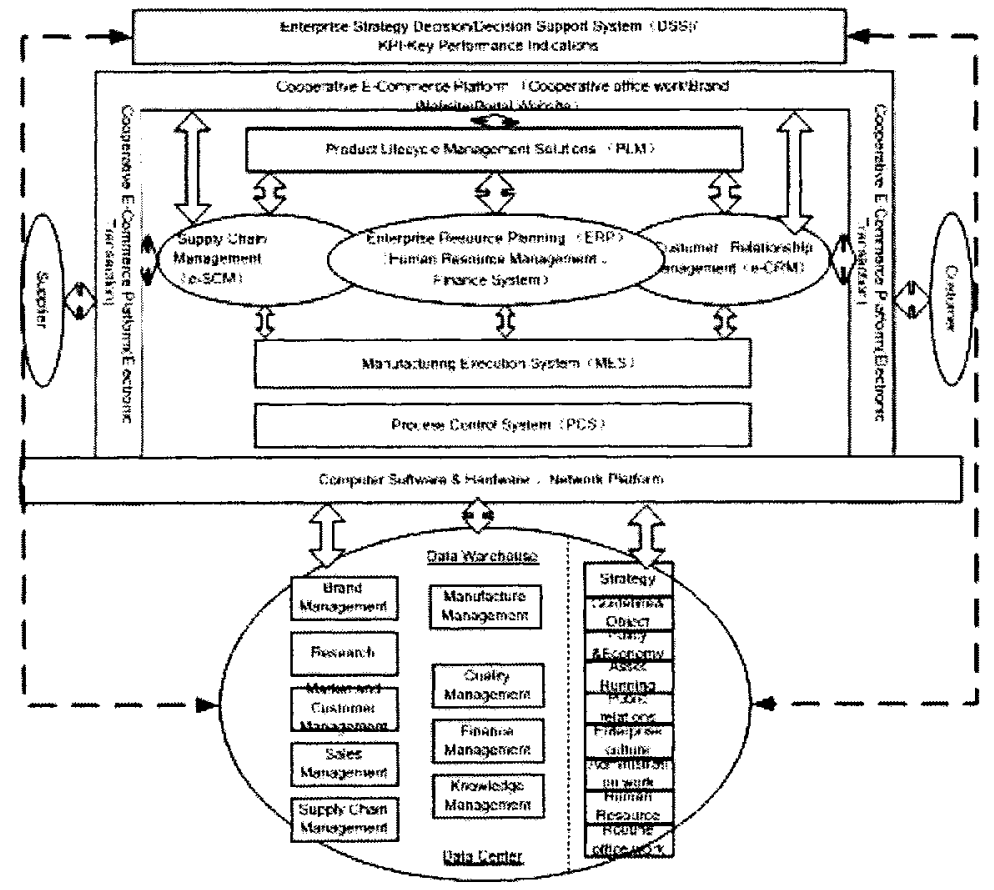

Figure. 3 Overall Information Technology Planning Framework

Specific, realize the data communication of long-distance customer and application server as well as WWW server using the agreements such as Http and TCP/IP. WWW server communicates through COM assembly /Web Service and the COM assembly agreement of /Web Service of Microsoft. It can makes user monitor 
the development processing and long-distance visit on-the-spot in customer end using standard webpage browser real time to control the data on-the-spot, in order to make the purpose of reaching telemonitoring and monitoring come true. The system designed according to the above goal, this system consist of operating the WWW server in local server, the server of Web Service, relation database, and of operating on data server ,such as data collection server and database of real time, of operating on customer end browser, as well as the data collection software composition on-thespot of real time.

(2) Systematic function design

This system refers to MES (manufacture execute system) model, systematic overall function configuration shows as Fig.5. The core of the system is production distribute management, realizing the real time management of the workers, equipments and stock, monitoring production process and offering analyze function about production to system.

- Production disposition

The product brand and stock catalog may get from the basic data management system of ERP system; Product constructer technology route may obtain from ERP systematic technology management subsystem; ERP systematic equipment management system included the basic dates such as equipment situation and equipment relationship.

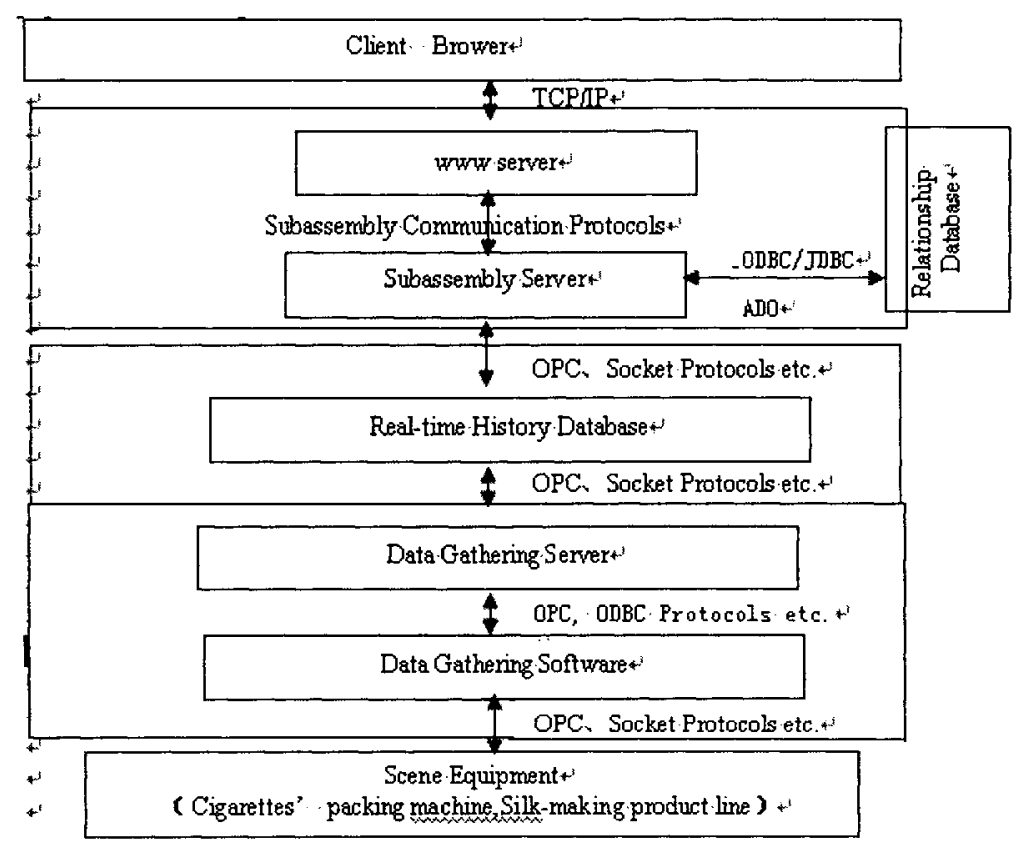

Figure. 4 MES Software Structure

- Resource management 
164 The Research on Enterprise Manufacture Integrated and Collaborative Commerce

System

This modular manages person and thing (raw material, supplement material and spare parts ), the productions such as equipment resource, which in order to guarantee production going on normally.

(1) staff manage

Offer staffs' state data information, including staffs' basic information and turn out for work, and the information such as business ability, the work of guiding various post people according to the change of people qualifications, working pattern and demand for service, in order to develops employee biggest subjective activity. Suggest realize the human resource management system in ERP, realize the integration and share the functions of human resource of ERP and MES on this foundation.

(2) Equipment management

Equipment management offers equipment basic data information as well as equipment working ability information, offer real time and the accuracy of basis and emphatic planned dispatching for planned dispatching.

System carries out flexible statistical analysis inquiry for the information such as the equipment operation state, fault, repair and task of real time in the aid of in various charts. At the same time, system realizes equipment information analysis in deeper level in the aid of in SPC statistical analysis control picture.

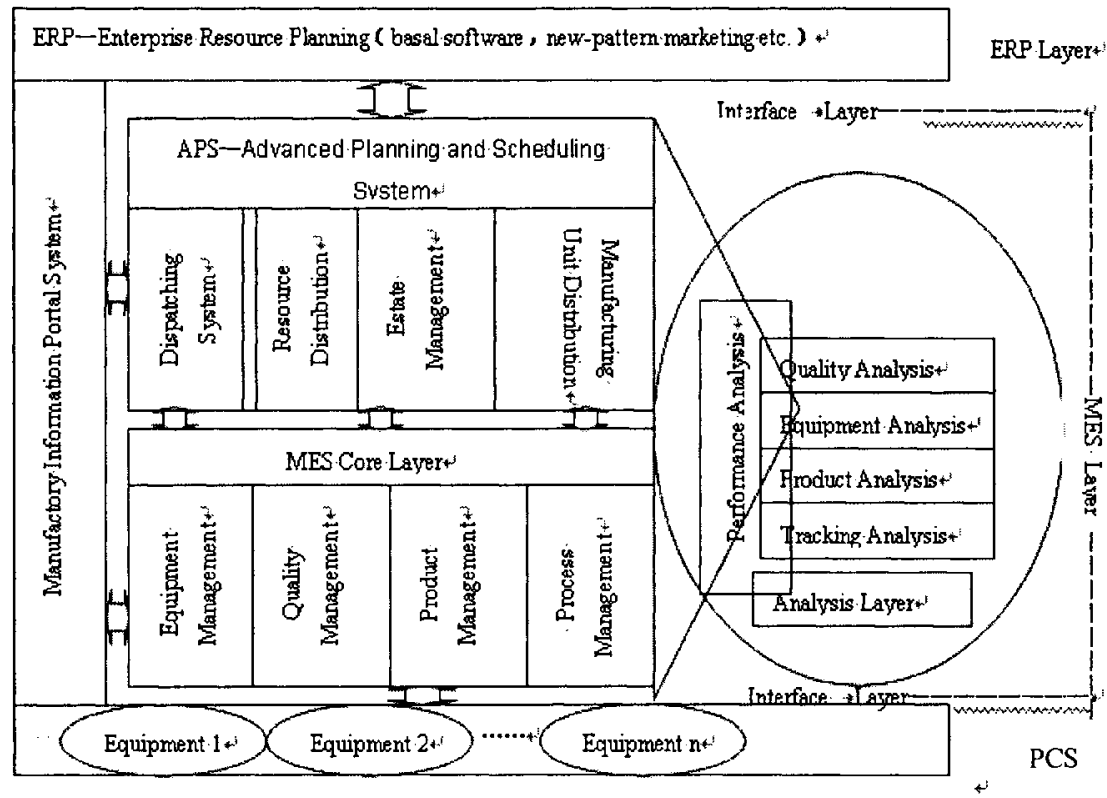

Figure. 5 MES Function Structure 
- Production management modules:

This modular is the key modular of this system, divides into some following son

(1) Production plan queues and is given:

Through the terminal on-the-spot, communicate production in time to workers of field work schoolwork plan and production schoolwork work sheet ( the list of production processing, the list of working central work sheet ), the information such as schoolwork procedure and schoolwork quality standard.

- Commodity circulation is managed

According to the detailed production plan, systematic automatic generation raw material and supplement material collar material application. They are delivered to ERP systematic tobacco management system and supplement material management system; Guide the production of the stocks such as stem silk and slice silk, guide expansion silk manage. In that way, the system can raise accuracy and the efficiency of commodity circulation, as well as production efficiency.

- Task execution track

By metering the condition of production plan going on Real time land, it is easy for produce management department to adjust production in time. It can trail to produce unit, workshop and the production planned executions such as factory level.

- Statistical inquiry and analysis

The way that offers various form and graph to melt wraps the product of line for making silk thread and roll to carry out inquiry statistics and analysis. Through the data collection systematic or handwork record on-the-spot of real time enter way, to each related production the production that people offer workshop has information real time, as well as workshop production has information record (include producing to plan record information, workshop schoolwork record information and machine schoolwork record information ) inquiry interface. Inquiry rank includes workshop level, production unit level and equipment level.

- Quality management

After analyzing and appraising the production process for workshop, it can reflects selected production process information to operation and administrator in different levels management units (workshop, unit and machine) ,such as product quality, equipment efficiency, stock consumption, equipment load ability and comprehensive capability index.

- Production process and production trace back

However it can not embody the character of MES system completely and the production management function only through tracing back to the process of making silk and roll bale, or getting the production management information such as output, brand and batch. At the same time, it can not carry out further use the MES system if we don't analysis trail information for these production processes completely.

\section{- Data collection}

Through the data system of the packing shop, it finishes the data receiving of the connecting machine, the output of the packer, the auxiliary materials consuming, and the equipment operation conditions, it offers basic data information, which will be calculated in the online production cost system in the future, and also is the basis that examines the workshop to ERP system.. 


\subsection{Melt in e-commerce platform in coordination.}

In coordination with the commercial concept, the purpose of the enterprise's information construction is not merely the inside resources of the management enterprises, it also needs to set up one unified platform, bring the customer, supplier, the retail trader and other cooperative partners into the enterprise's information-based administrative system, make all of enterprises data integrate to a information management platform, and offer to the users with an unified user's interface, implement a series of chaining of the high-efficient sharing and business of information. "Work in coordination with

The Melt in e-commerce platform in coordination is shown in the following figure 6:

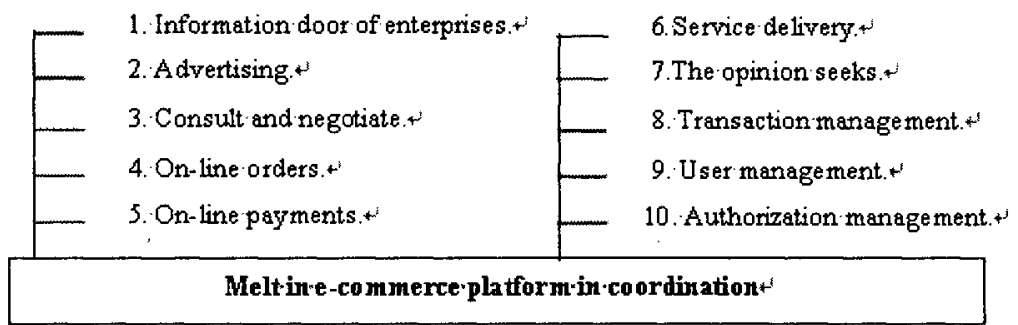

Fig.6 Melt in e-commerce platform in coondination ${ }^{+}$

\section{Conclusion}

After more analysis research in detail, we may approximately understanding the present situation of Xuzhou Cigarette Factory informative construction At present, the project is being implemented smoothly as planned. It must be a fundamental change to the operating mechanism and management system while bringing remarkable direct economic efficiency. Then has a profound influence to enterprise's development.

\section{References}

1. Zhu Guan Zhou, "Chinese ERP market's situation report", PC World,2002(2)

2. HongTao, "Advanced e-bussiness study course," Economic Management Press,2003(4)

3. Xue Jian, "The thinking of Chinese enterprise in conformity with ERP" ,The industrial journal of higher junior college of Chong Qing,2003,(12)

4. Liu NaXin, "The comparative analysis of the management software of ERP using in the enterprise", Problem and study2003,(12)

5. SUN Shudong ,DENG Weimin, XIE Guiliang. "Job shop management system based on cost control". China Machine Engineering, 2001, 12 (3):322 - 324 (in Chinese) 